\title{
Successful Cerebral Hemorrhage Control with Prothrombin Complex Concentrate in a Patient on Edoxaban Therapy: A Case Report
}

This article was published in the following Dove Press journal:

Journal of Blood Medicine

\section{Giuseppe Galbiati}

Emergency Department, Policlinico San Marco, Zingonia, BG, Italy
Correspondence: Giuseppe Galbiati

Emergency Department,

Policlinico San Marco, Zingonia, BG, Italy Tel +39035886445

Email galbiati.g@libero.it

\begin{abstract}
Direct oral anticoagulants (DOACs) have demonstrated safety and efficacy in stroke prevention in patients with non-valvular atrial fibrillation (NVAF). In terms of safety, there was a significant reduction of intracranial hemorrhages (ICH) in patients treated with DOACs over warfarin. To date, a specific antidote for edoxaban is not yet available. The management of ICH relies on the use of coagulation factors. This article reports a case of a 73-year-old woman with NVAF who had cerebral hematoma in the right intraparenchymal thalamus-capsular area while on therapy with edoxaban $60 \mathrm{mg} /$ day. The computed tomography (CT) brain scan showed hematoma of $>18 \mathrm{~mm}$ diameter. The patient was timely treated with four-factor prothrombin complex concentrate (4F-PCC) at $50 \mathrm{IU} / \mathrm{kg}$. After $6 \mathrm{hrs}$ patient's symptoms alleviated and she was successfully recovered within 6 days. A repeated CT scan of the brain in 3 weeks showed improvement. The patient's treatment with edoxaban $30 \mathrm{mg}$ /day restarted after 8 weeks.
\end{abstract}

Keywords: non-valvular atrial fibrillation, edoxaban, prothrombin complex concentrate, cerebral hemorrhage

\section{Background}

Direct oral anticoagulants (DOACs) have demonstrated safety and efficacy in stroke prevention in patients with non-valvular atrial fibrillation (NVAF). Overall, intracranial hemorrhage $(\mathrm{ICH})$ reduction has been significant with all 4 DOACs as compared to warfarin. ${ }^{1-3}$ Currently, only idarucizumab, ${ }^{4}$ the specific antidote for dabigatran, is available on the market. Idarucizumab is a humanized monoclonal antibody fragment that binds with a high affinity to free and thrombin-bound dabigatran, neutralizing its anticoagulant activity.

On the other hand, reversal agents for anticoagulants binding to factor Xa are still under investigation. Andexanet alfa, a modified recombinant inactive form of human factor Xa, has been recently approved by the European Medicines Agency (EMA) but is not on the market yet. It has shown a marked reduction of anti-factor Xa activity and $82 \%$ of patients had excellent or good hemostatic efficacy at $12 \mathrm{hrs}^{5}$ In situations where a specific reversal agent is not available current guidelines ${ }^{6-8}$ recommend $^{6}$ administration of prothrombin complex concentrates (PCCs) or activated PCCs in patients with life-threatening bleeding when immediate hemostatic support is required.

Four-factor prothrombin complex concentrate (4F-PCC) contains factors II, VII, IX, and $\mathrm{X}$ that can temporarily correct coagulation deficits. The complex of tissue 
factor with factor-VIIa activates the coagulation factors IX, X, (IXa, Xa) that lead to the activation of prothrombin in thrombin thus reversing factor Xa inhibition. ${ }^{9}$ Edoxaban is the only anti-Xa inhibitor agent to have data on the effects of four-factor prothrombin complex concentrate (4F-PCC) on the reversal of bleeding. In a study of healthy subjects, the administration of a $4 \mathrm{~F}-\mathrm{PCC}$ at $50 \mathrm{IU} / \mathrm{kg}$ has shown to reverse the effects of edoxaban 30 mins after completing the infusion. ${ }^{10}$ The summary of product characteristics considers this data and advises its use to control life-threatening bleeding. ${ }^{11}$ Nonetheless, there is limited clinical data on the efficacy and safety of 4FPCC in patients treated with DOACs.

\section{Ethics}

Patient provided a written informed consent allowing the publication of the case details and accompanying images; the privacy of the patient was maintained with confidentiality. Due to the retrospective nature of the case institutional approval was not required

\section{Case Report}

A 73-year-old female patient arrived at the Policlinico San Marco Emergency Department, Zingonia (BG), Italy, at $9.52 \mathrm{am}$. She reported the onset of a severe headache occurred $1 \mathrm{hr}$ earlier, she woke up at around 7.00 am after a normal night. She also complained about the difficult use of the remote control of the TV with the left hand (left-handed person). Her relatives reported that she had labial commissure deviation and was confused. Upon arrival at the Emergency Department, the patient had a physical examination performed. The patient was in overall good conditions, awake, opening eyes spontaneously, verbally well orientated to time, person and place, followed motor commands and collaborative, her Glasgow Coma Scale (GCS) was 15. Vital signs included a body temperature of $36.8^{\circ} \mathrm{C}$ with well-perfused skin and valid capillary refill (less than 2 seconds), blood pressure of 174/82 $\mathrm{mmHg}$, pulse rate of $76 \mathrm{bpm}$ with rhythmic cardiac sounds and punctual flow murmurs, mild polypnea and oxygen saturation of $98 \%$. The patient had visual analog scale (VAS) evaluation of 4, hypoesthesia of the left arm (positive Mingazzini I), labial commissure deviation, mild dysarthria, and left decubitus while semi-tilting, $\mathrm{CHA}_{2} \mathrm{DS}_{2}$-VASc score: 4 , creatinine 1.0 $\mathrm{mg} / \mathrm{dl}$, creatinine clearance: $51 \mathrm{ml} / \mathrm{min}$. The patient stated she was on treatment with edoxaban 60mg QD,

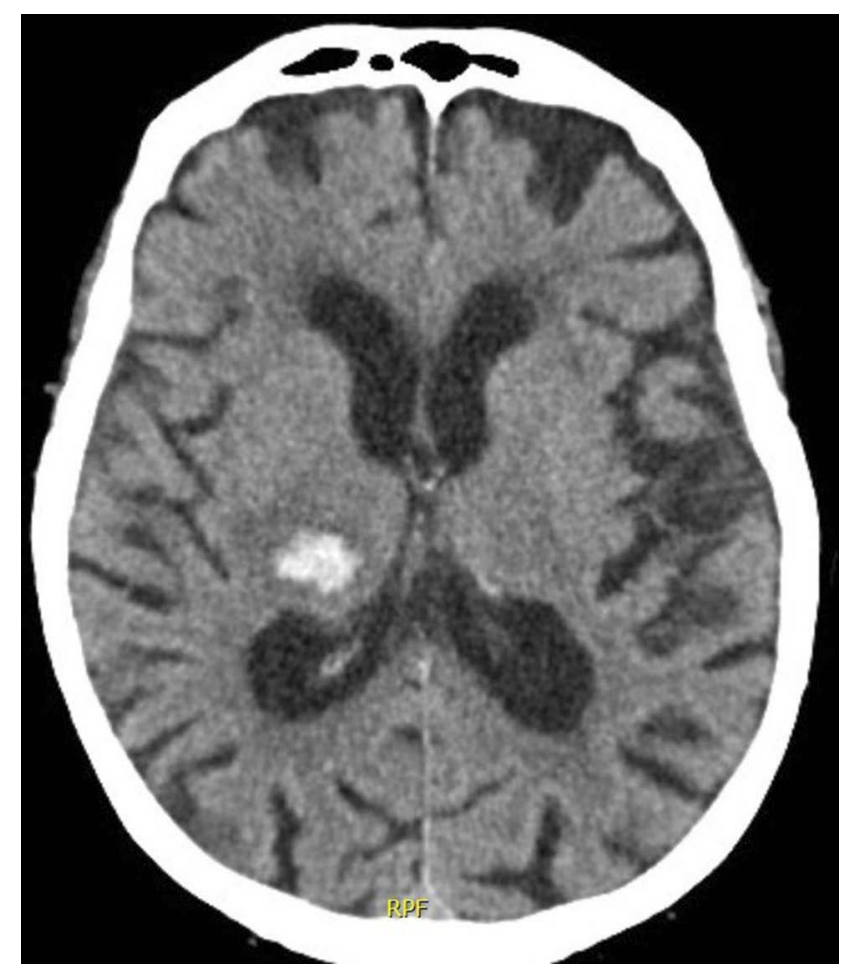

Figure I Cranial CT scan upon arrival to the emergency department.

and she took the last dose at $8 \mathrm{pm}$ the evening before. Concomitant therapies included: bisoprolol $1.25 \mathrm{mg}$ QD, telmisartan/hydrochlorothiazide $\quad 80 \mathrm{mg} / 12.5 \mathrm{mg}$ QD, atorvastatin 10mg QD, and citalopram 20mg BID.

Medical history comprises right hip prosthesis in 1998, left hemicolectomy due to adenocarcinoma of the colon in 2003, hypertension, persistent NVAF in treatment with oral anticoagulant therapy with warfarin since 2005 and pacemaker implantation due to symptomatic bradyarrhythmia in 2007. Since March 2018, warfarin was replaced with edoxaban $60 \mathrm{mg}$ QD.

Blood tests showed prolonged prothrombin time at 29 sec (with reduced factor Xa and normal fibrinogen) and INR 3.57. Other relevant blood values were in normal range and included: platelets $173 \times 10^{9} / \mathrm{L}$, hemoglobin $13.9 \mathrm{~g} / \mathrm{dL}, \mathrm{MCV} 91.2 \mathrm{fL}$, urea $24 \mathrm{mg} / \mathrm{dL}$, glycemia $117 \mathrm{mg} / \mathrm{dL}$, AST $20 \mathrm{U} / \mathrm{L}$, ALT $11 \mathrm{U} / \mathrm{L}$, direct bilirubin $0.18 \mathrm{mg} / \mathrm{dL}$, reactive $\mathrm{C}$ protein $1.3 \mathrm{mg} / \mathrm{L}$, myoglobin 56 $\mathrm{ng} / \mathrm{mL}$, amylase $35 \mathrm{UI} / \mathrm{L}$. CT brain scan showed hematoma of $>18 \mathrm{~mm}$ diameter in the right intraparenchymal thalamus-capsular area without compression of the 3rd ventricle and with peripheric edematous halo (Figure 1). Patient was diagnosed with a cerebral hemorrhage during treatment with edoxaban $60 \mathrm{mg}$. 


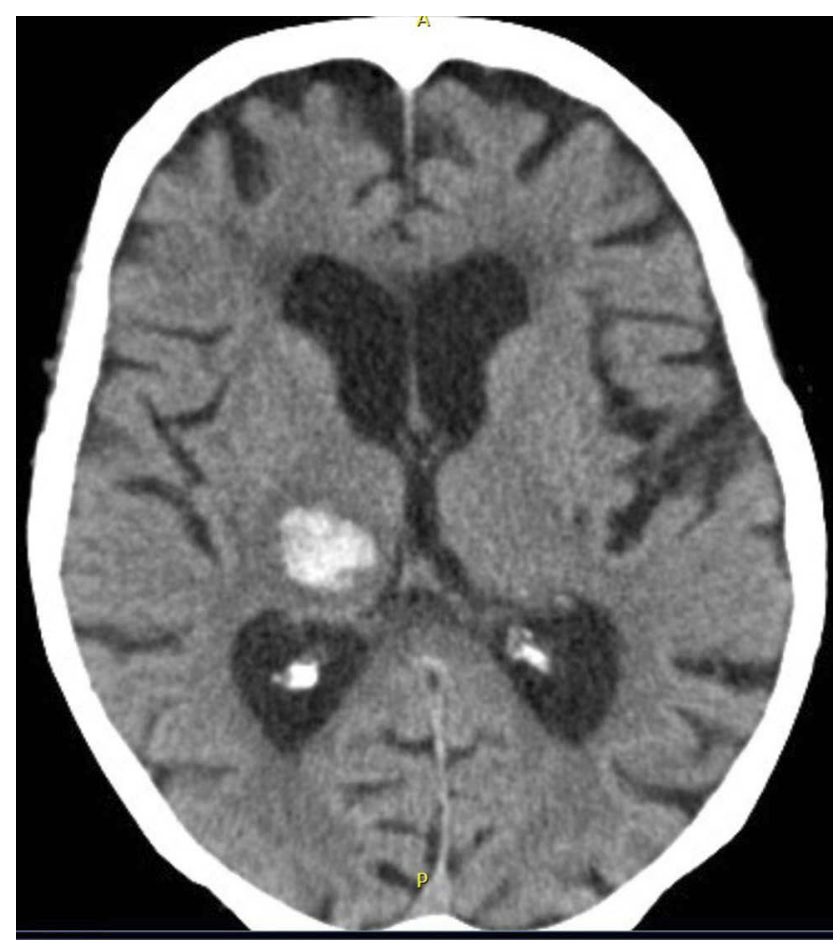

Figure 2 Cranial CT scan at 6 hrs.

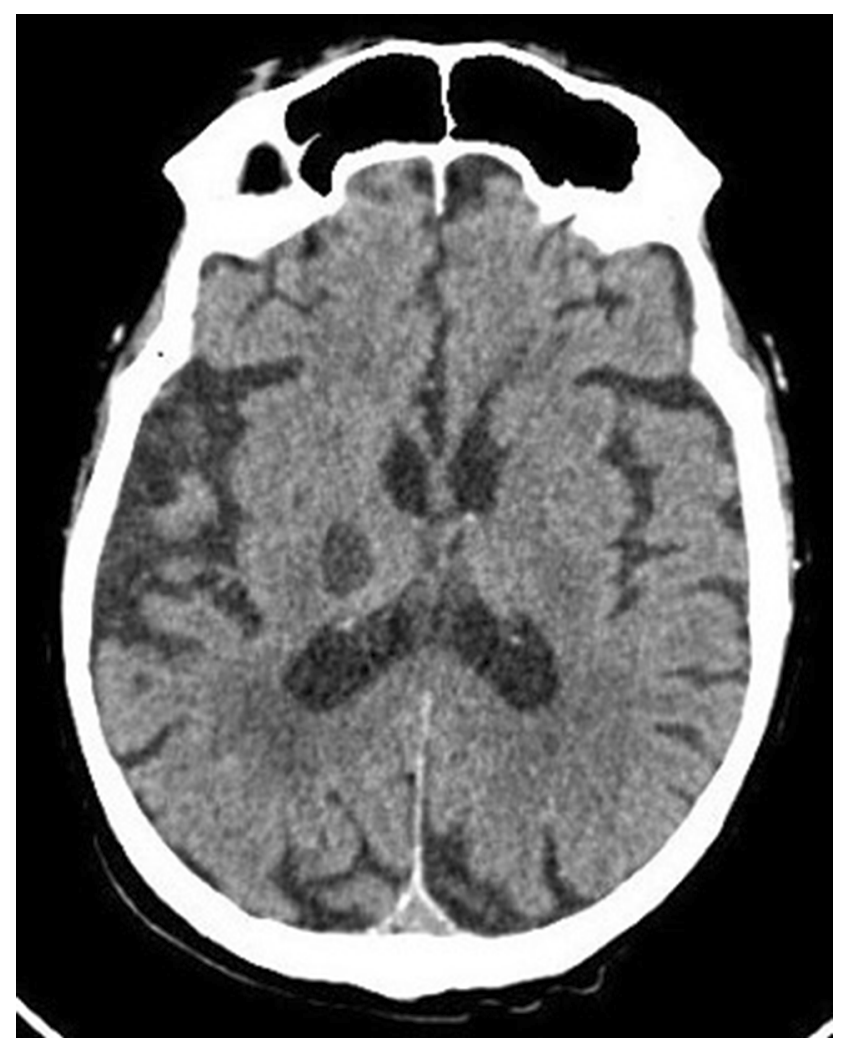

Figure 3 Cranial CT scan at 3 weeks.

Labetalol was infused with bolus for maintenance of correct pressure values, dexamethasone IV; perfusion with $4 \mathrm{~F}-\mathrm{PCC}$ at $50 \mathrm{UI} / \mathrm{kg}$ was started. After 30 mins of infusion, blood pressure was $135 / 75 \mathrm{mmHg}$, blood tests showed prothrombin time at $92 \%$, normalization of factor $\mathrm{Xa}$ and INR 1.06. A new CT scan was performed after $6 \mathrm{hrs}$ indicating unchanged hemorrhage (Figure 2). Dysarthria and headache improved while hypoesthesia of the left arm persisted.

The patient was transferred to the Stroke Unit, where enoxaparin 4000 IU QD, dexamethasone $8 \mathrm{mg}$ IV BID, olmesartan and lercanidipine were administered. In the following 6 days, she had a good improvement of the left arm mobility, proper speech, completely regained the ability to walk without assistance. Cardiac frequency and pressure values were normal. The patient was discharged after 6 days in good conditions, stable pressure values and fully recovered. Her therapy comprises bisoprolol $1.25 \mathrm{mg}$ QD, telmisartan/hydrochlorothiazide $80 \mathrm{mg} / 12.5 \mathrm{mg} \mathrm{QD}$, atorvastatin $10 \mathrm{mg} \mathrm{QD}$, pantoprazole $20 \mathrm{mg}$ QD and enoxaparin $4000 \mathrm{UI} /$ day.

CT scan was performed at 3 weeks showing improvement of brain hematoma (Figure 3). After 8 weeks, given the clinical stability as well as considering patient's weight of $64 \mathrm{~kg}$, creatinine clearance of $48 \mathrm{~mL} / \mathrm{min}$ (creatinine $1.05 \mathrm{mg} / \mathrm{dL}$ ) and a worsened HAS-BLED score from 3 to 4 anticoagulation was restarted with edoxaban $30 \mathrm{mg} /$ day. Citalopram treatment was not resumed at this stage.

\section{Discussion}

The Phase III DOAC studies have consistently shown that DOACs cause less intracranial and less life-threatening bleedings than warfarin, despite the absence of reversal strategies in these trials. ${ }^{2,3}$ Guidelines' recommendations mostly drive the management of bleeding. The latest EHRA Practical Guide recommends a hospital-wide policy concerning bleeding control under DOAC, depending on the availability and indications of specific coagulation tests as well as of specific and nonspecific reversal agents and the clinical setting. For patients who undergo life-threatening bleeding, the EHRA Practical Guide suggests the administration of specific reversal agents as well as PCC or aPCC. ${ }^{7}$ The CHEST Guideline $2018^{8}$ recommends using a DOACspecific reversal agent or PCC if reversal agent not available for patients with severe or life-threatening bleeding.

Specific reversal agents have been designed based on various rationale. Idarucizumab is a humanized monoclonal antibody that binds specifically dabigatran. ${ }^{4}$ While, andexanet alfa is a recombinant human factor 
$\mathrm{Xa}$ analog that competes with factor $\mathrm{Xa}$ to bind factor Xa inhibitors. ${ }^{5}$ Ciraparantag (PER 977), specific for factor Xa inhibitors is a small synthetic molecule that seems to have more generalized antagonistic effects. ${ }^{12}$ The last two antidotes are undergoing clinical testing. 4F-PCC, on the other hand already contains human factors II, VII, IX, and X that increase the concentration of vitamin $\mathrm{K}$ dependent coagulation factors above normal generating more factor $\mathrm{Xa}$ and thrombin that escapes from DOAC inhibition, resulting in increased feedback amplification of the coagulation processes. ${ }^{9}$

In a Phase I study in healthy volunteers, intravenous 4FPCC dose-dependently reversed the effects of edoxaban $60 \mathrm{mg}$, and suggest that 4F-PCC represents a readily available option in cases where rapid reversal of edoxaban anticoagulation is essential. The double-blind, randomized, placebo-controlled, study determined the reversal effect of descending doses of 4F-PCC on bleeding duration and bleeding volume following edoxaban treatment. There was a dose-dependent reversal of the effects of edoxaban on bleeding duration, with complete reversal at $50 \mathrm{IU} / \mathrm{kg}$. ${ }^{11}$ This information is relative to healthy subjects and it is not clear if it can be translated on elderly patients with ICH. Elderly patients often have coexisting characteristics like morbidities, frailty, polypharmacy, high bleeding and high thromboembolic risk and are therefore at a greater risk of hemodynamic imbalances. ${ }^{6,13}$

In this case, for example, the co-administration of edoxaban and citalopram might have been relevant. It is now recognized that patients on DOAC treatment are at increased risk of bleeding in case of concomitant use of SSRIs or SNRIs due to their reported effects on platelets. ${ }^{11}$

This case report confirms that 4F-PCC can be used to control effectively life-threatening endocranial bleeding in patients taking edoxaban. Such finding is clinically meaningful, given the antidote for factor $\mathrm{Xa}$ inhibitor is not marketed yet.

\section{Disclosure}

The author reports no conflicts of interest in this work.

\section{References}

1. Giugliano RP, Ruff CT, Braunwald E, et al. Edoxaban versus warfarin in patients with atrial fibrillation. $N$ Engl $J$ Med. 2013;369:2093-2104. doi:10.1056/NEJMoa1310907

2. Ruff CT, Giugliano RP, Braunwald E, et al. Comparison of the efficacy and safety of new oral anticoagulants with warfarin in patients with atrial fibrillation: a meta-analysis of randomised trials. Lancet. 2014;383:955-962. doi:10.1016/S0140-6736(13)62343-0

3. Caldeira D, Barra M, Pinto FJ, et al. Intracranial hemorrhage risk with the new oral anticoagulants: a systematic review and metaanalysis. J Neurol. 2015;262:516-522. doi:10.1007/s00415014-7462-0

4. Pollack Jr CV, Reilly PA, Van Ryn J, et al. Idarucizumab for dabigatran reversal - full cohort analysis. N Engl J Med. 2017;377(5):431441.

5. Connolly SJ, Crowther M, Eikelboom JW, et al. Full study report of andexanet alfa for bleeding associated with factor Xa inhibitors. N Engl J Med. 2019;380:1326-1335. doi:10.1056/NEJMoa1814051

6. Steffel J, Verhamme P, Potpara TS, et al. The 2018 European heart rhythm association practical guide on the use of non-vitamin $\mathrm{K}$ antagonist oral anticoagulants in patients with atrial fibrillation. Eur Heart J. 2018;39:1-64.

7. Lip GYH, Banerjee A, Boriani G et al. Antithrombotic Therapy for Atrial Fibrillation, CHEST Guideline and Expert Panel Report. CHEST 2018; 154(5):1121-1201

8. Raval AN, Cigarroa JE, Chung MK, et al. Management of Patients on Non-Vitamin K Antagonist Oral Anticoagulants in the Acute Care and Periprocedural Setting: A Scientific Statement from the American Heart Association, Circulation. 2017;135(10):e604-e633

9. Brinkman HJM. Prothrombin Complex Concentrate, a General Antidote for Oral Anticoagulation. In: Anticoagulation Therapy. London, UK: IntechOpen; 2016, 79-109.

10. Zahir H, Brown KS, Vandell AG, et al. Edoxaban effects on bleeding following punch biopsy and reversal by a 4-factor prothrombin complex concentrate. Circulation. 2015;131:82-90. doi:10.1161/ CIRCULATIONAHA.114.013445

11. Daiichi Sankyo Europe GmbH. Lixiana (Edoxaban) summary of product characteristics. Daiichi Sankyo Europe GmbH; May 2019.

12. Ansell JE, Bakhru SH, Laulicht BE, et al. Use of PER977 to reverse the anticoagulant effect of edoxaban. N Engl J Med. 2014;371:21412142

13. Kato ET, Giugliano RP, Ruff CT, et al. Efficacy and safety of edoxaban in elderly patients with atrial fibrillation in the ENGAGE AF-TIMI 48 trial. J Am Heart Assoc. 2016;5:5.
Journal of Blood Medicine

\section{Publish your work in this journal}

The Journal of Blood Medicine is an international, peer-reviewed, open access, online journal publishing laboratory, experimental and clinical aspects of all aspect pertaining to blood based medicine including but not limited to: Transfusion Medicine; Blood collection, Donor issues, Transmittable diseases, and Blood banking logistics; Immunohematology; Artificial and alternative blood based therapeutics; Hematology; Biotechnology/nanotechnology of blood related medicine; Legal aspects of blood medicine; Historical perspectives. The manuscript management system is completely online and includes a very quick and fair peer-review system. Visit http://www.dovepress.com/testimonials.php to read real quotes from published authors. 